\title{
Smart Dustbins - Automatic Segregation \& Efficient Solid Waste Management using IoT Solutions for Smart Cities
}

\author{
Viral Rambhia \\ KJSCE, Mumbai, India
}

\author{
Aman Valera \\ KJSCE, Mumbai, India
}

\author{
Rahul Punjabi \\ KJSCE, Mumbai, India
}

\author{
Shweta Dhawan Chachra \\ Project Guide \\ Assistant Professor, \\ Computer Department, \\ K.J. Somaiya College of Engineering \\ Vidyavihar, Mumbai
}

\begin{abstract}
Sustainability is the ability to exist continually. In the 21st century, it generally refers to the capacity for the biosphere and human civilization to coexist. There has been a spike in solid waste generation in recent times. Solid waste management is a crucial issue towards global sustainability crises. Governments across the world are taking initiatives to transform cities into smart cities. An appropriate mechanism for solid waste collection and management is vital for bringing this change. The economic value of waste is not realized unless it is appropriately managed. Internet of Things (IoT) Technologies can efficiently handle such services in smart cities. Way to sustainability is an efficient use of technology to achieve solutions to global environmental problems; solid waste management is one of the significant issues. In this paper, we are proposing an IoT based Smart dustbin monitoring system with dynamic scheduling and routing of trash collector along with moisture detection of smart dustbins. Real-time status of each smart bin is sent to the cloud. A mobile application assists the trash collector using optimal dynamic routes. Municipal corporations monitor the entire waste collection process using the proposed system. We also propose a way to automatically segregate wet and dry waste using moisture detection.
\end{abstract}

Keywords - Automatic segregation, Cloud, Dynamic scheduling, Route optimization, Solid waste management, Smart cities, WetDry waste segregation.

\section{INTRODUCTION}

The Internet of Things (IoT) is trending with its ever expanding Eco-system of digital sensors, appliances and wearable smart devices. Like other sectors, the role of IoT in sustainable development and environment protection will be crucial in the coming years. The growth of the world's population, increasing urbanization, rising standards of living, and rapid developments in technology have all contributed to an increase in both the amount and the variety of solid wastes generated by industrial, domestic and other activities. The traditional methods of waste collection are found very inefficient to handle the waste. This has led to development of smart solid waste management systems which will help us solve these problems or at least reduce it to certain extent.

In many cities, we find garbage bins overflown at various public places in cities due to an increase in waste. It creates unhygienic surroundings and lousy odour, which leads to the spread of deadly diseases and human illness. In today's era, most of the metro cities are in the transformation phase and likely to reformed as smart cities. To evade an unhygienic situation caused because of inferior garbage collection methods, we propose to design an IoT based Waste Management System for Smart Cities. In this proposed system, there will be multiple garbage bins positioned throughout the city or campus; these garbage bins will be set up with low cost embedded device, which helps in tracking the level of garbage in a particular bin along with location tracking module to get the real-time location of bin. All the real-time information, including garbage level as well as the location of that bin, will be sent frequently to concern authority and garbage collector truck driver as well. The truck driver will have an android application, which will show real-time information about all bins to the driver that which bin is how much full. The system also proposes a way to automatically segregate wet and dry waste based on moisture content of waste.

\section{RELATED WORK}

Tremendous research has been done on waste management throughout the world. Most of which were focusing on manual collection of waste, its dissemination, and it's recycling. It's in recent years that people have started using technology for monitoring and efficiently collecting the waste. Mahajan and Chitode [4] have proposed Zig-Bee 
based waste bins monitoring system. The sensors placed in the garbage bins sense the level of garbage in the garbage bin, and the status of garbage bin is communicated to garbage collection truck driver using short messaging service. A similar approach is proposed by Gupta and Kumar [5]. They have utilized RFID and GSM technology for communicating the status of garbage bins. In the proposed system proposed by Bhor [6], the extent of garbage in the bins is spotted with the help of Sensor systems, and communicated to the authorized control room through GSM system. To monitor the required information related to garbage bins at different selected locations, a GUI is also developed. This will increase the efficiency of garbage collection management. Smart bins concept for waste collection management for an entire city is proposed in [7]. Smart bins level indicator data is collected using a sensor network connected to bins and further analyzed and visualized to illustrate the real status of waste in the city. Existing systems are not able to transmit the status of garbage bins And the calculation of the optimized route simultaneously. So there is a need to develop a system which will show real-time status of Garbage bins and at the same time show and show optimized the route to garbage collection truck driver to reach the garbage

bins. Looking into background research regarding the untidy or mismanagement of garbage collection system, IoT enabled solid waste management system is studied with the following objectives.

The collective aim of this project is to assist Municipal Corporation and garbage collector contractors to efficiently monitor and collect solid waste from garbage bins in their region using IoT enabled solid waste management system. It will serve as a dynamic service. Also we have attempted to automatically separate wet and dry waste based on readings of moisture sensor, this will eliminate the need to use two separate bins for type of waste. Automatic segregation will also simplify process for pedestrians to identify the type of bin they need to throw garbage in.

\section{PROPOSED SYSTEM}

\section{A. SYSTEM ARCHITECTURE}

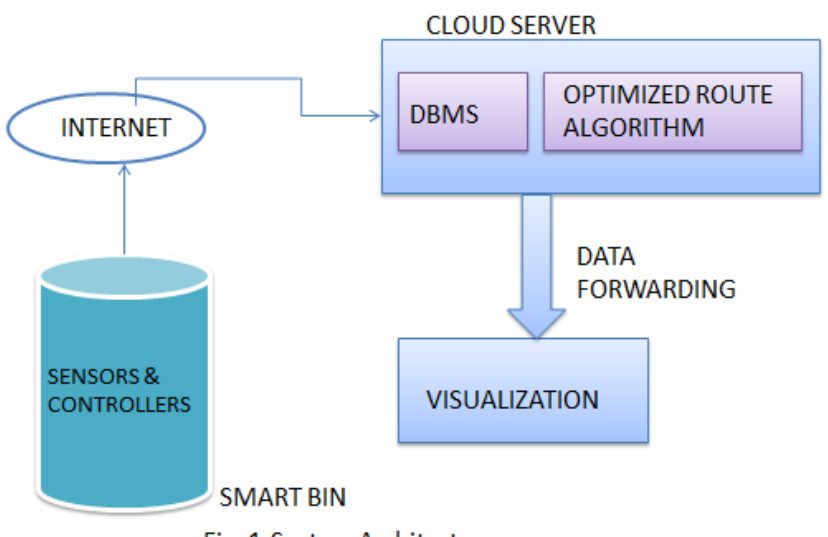

Figure 1 shows the basic system architecture. The smart bin will sense data through sensors, actuators will control automatic opening and closing of bin. Cloud server will manage data and calculate optimized routes. These routes will be visualized through an android application.

\section{B. AUTOMATIC SEGREGATION OF WET AND DRY WASTE}

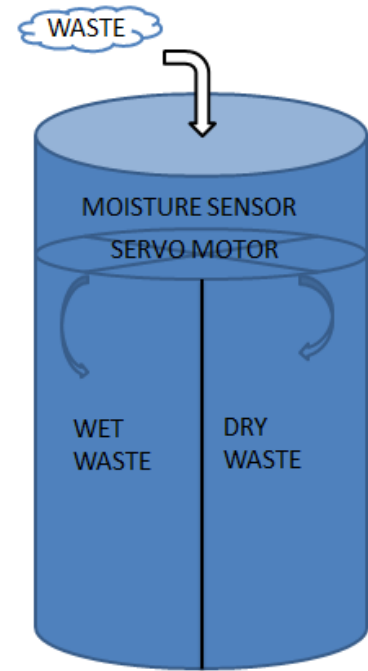

Fig. 2: Bin Design for automatic segregation

The moisture sensor will be placed in the area between opening of bin and the seprator panel. If the garbage thrown is detected as wet, the servo motor will rotate in a direction of wet collector, else the servo motor will rotate toward dry side.

\section{AUTOMATIC OPENING AND CLOSING OF SMART $B I N$}

The automatic opening and closing of bin is implemented using ultrasonic sensor.

HC-SR04 Ultrasonic Sensor

Features:

- Operating voltage: $+5 \mathrm{~V}$

- Theoretical Measuring Distance: $2 \mathrm{~cm}$ to $450 \mathrm{~cm}$

- Practical Measuring Distance: $2 \mathrm{~cm}$ to $80 \mathrm{~cm}$

- Accuracy: $3 \mathrm{~mm}$

- Measuring angle covered: $<15^{\circ}$

- Operating Current: $<15 \mathrm{~mA}$

- Operating Frequency: $40 \mathrm{~Hz}$

Arduino IDE is used to upload code to Arduino. The system is encoded such that, if any object is detected within distance of $35 \mathrm{~cm}$, the lid opens. The lid is open for $2 \mathrm{sec}$ and if it further detects no object it automatically closes. 


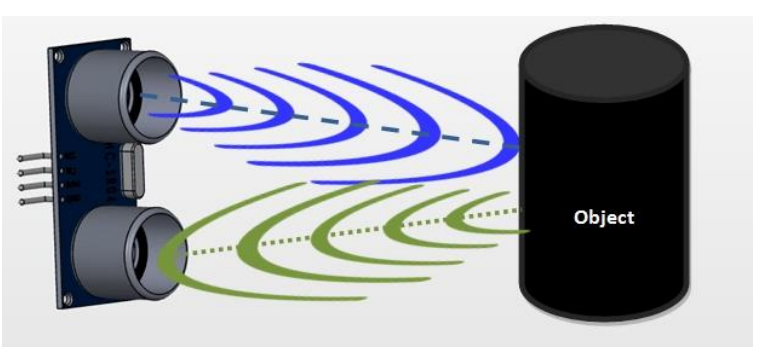

Fig. 3: Working of Ultrasonic Sensor

Following figure shows actual implementation image of automatic opening and closing of lid.
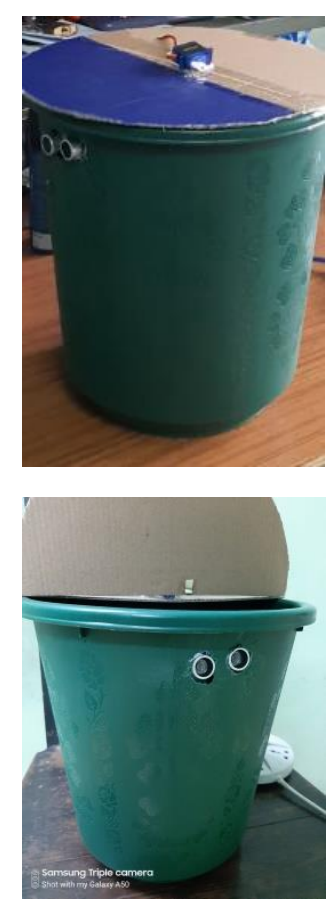

\section{IMPLEMENTATION}

We have developed an IoT enabled Waste Management system for smart cities in which garbage bin will be provided with ultrasonic sensor to sense the level of garbage along with GPS module to get real time location of bin, together will sent to cloud through internet and will be analyzed to give utility based android application for truck driver. The open-source Arduino Software (IDE) is used for writing a code and uploads it to the board. The environment is written in Java. This software is used with Arduino UNO R3 board. The data which is sensed by HCSR04 along with location information will be sent over the internet through Wi- Fi Module ESP8266. Transmitted data will be collected at cloud so we will be able to access data from anywhere using internet. The continuously sensed data from garbage bins are stored in cloud server and can be further used by both Waste management authority and as well garbage collection truck drivers.
Sensors: We can determine the waste level by measuring the distance from the top of the smart bin to the waste by sonar. The sonar that can be used in this prototype should provide measurement from $2 \mathrm{~cm}$ to $400 \mathrm{~cm}$ with $3 \mathrm{~mm}$ accuracy, which is adequate for typical smart bins, e.g., Ultrasonic Ranging Module (HC-SR04). It is essential to optimize the battery usage for achieving bigger lifespan of the devices. Sensing and data forwarding rates, and wireless technology used have a strong influence on energy consumption. Collection and forwarding of data can be done once or twice in a day. The presence of water/moisture is detected by using water brick.

Access Network Interface: The data collected is sent to a remote server via a wireless link. For our work, Wi-Fi is considered as a network access technology.

Database: MySQL is used for storage of all data collected by the sensors and the trucks.

Optimization algorithms: Once the identification of waste bins have been done, shortest path for collection of same is done. In this work, shortest path algorithm is followed for optimization.

Information adaptation and forwarding: The destination path must be sent to the collectors in understandable format.

\section{A. ALGORITHM FOR SHORTEST PATH USED BY SERVER}

Inputs: Distance from waste bins to worker stations.

Output: Optimized routes between two points where the waste bin needs to be collected.

\section{Description:}

1: consider street network as a graph;

2: consider street segments as edges and joining points as Vertices.

3: calculate an accurate shortest travelling distance between two locations.

4: calculate the distance from one-to-all waste bins to speed up the route optimization process. 
B. CIRCUIT CONNECTION FOR AUTOMATIC OPENING AND CLOSING OF SMART BIN

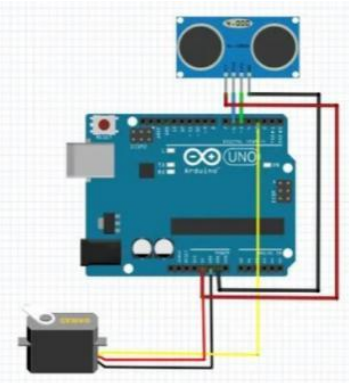

- Servo data (yellow) to pin 3 of Arduino

- Servo vcc (red) to 5v of Arduino

- Servo ground (black/gray) to Arduino Gnd

- Sonar sensor trig to Arduino 6

- Sonar sensor echo to Arduino 5

- Vcc to Arduino 5v

- Gnd to Arduino Gnd

C. DETECTION OF WET AND DRY WASTE

Water sensor brick is designed for water detection, which can be widely used in sensing rainfall, water level, and even liquid leakage. Water sensor brick along with moisture sensor will be used to segregate wet and dry waste.

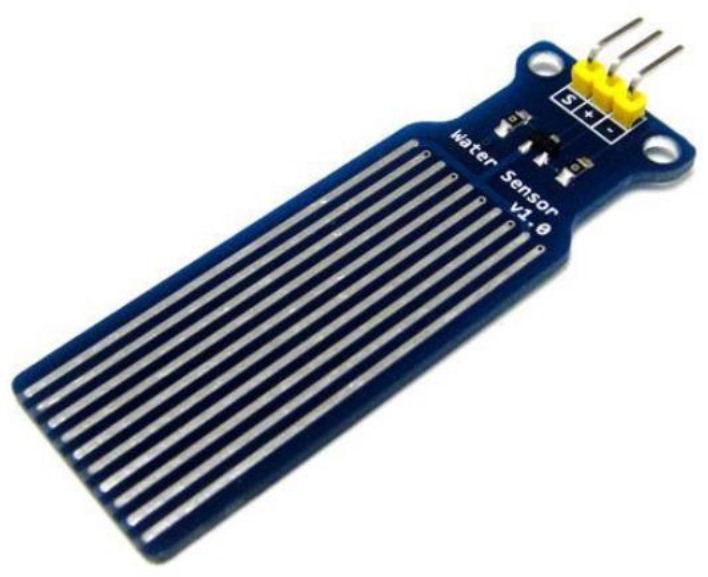

Fig. Water Sensor Brick

It can be used to detect the presence, the level, the volume and/or the absence of water. The sensor has an array of exposed traces, which read LOW when water is detected.
Following circuit diagram is connection of water brick with Arduino, for moisture detection.

Water sensor has three terminals - S, Vout(+), and GND (). Connect the sensor as follows -

Connect the $+\mathrm{Vs}$ to $+5 \mathrm{v}$ on your Arduino board.

Connect $\mathrm{S}$ to digital pin number 8 on Arduino board.

Connect GND with GND on Arduino.

Connect LED to digital pin number 9 in Arduino board.

When the sensor detects water, pin 8 on Arduino becomes LOW and then the LED on Arduino is turned ON.
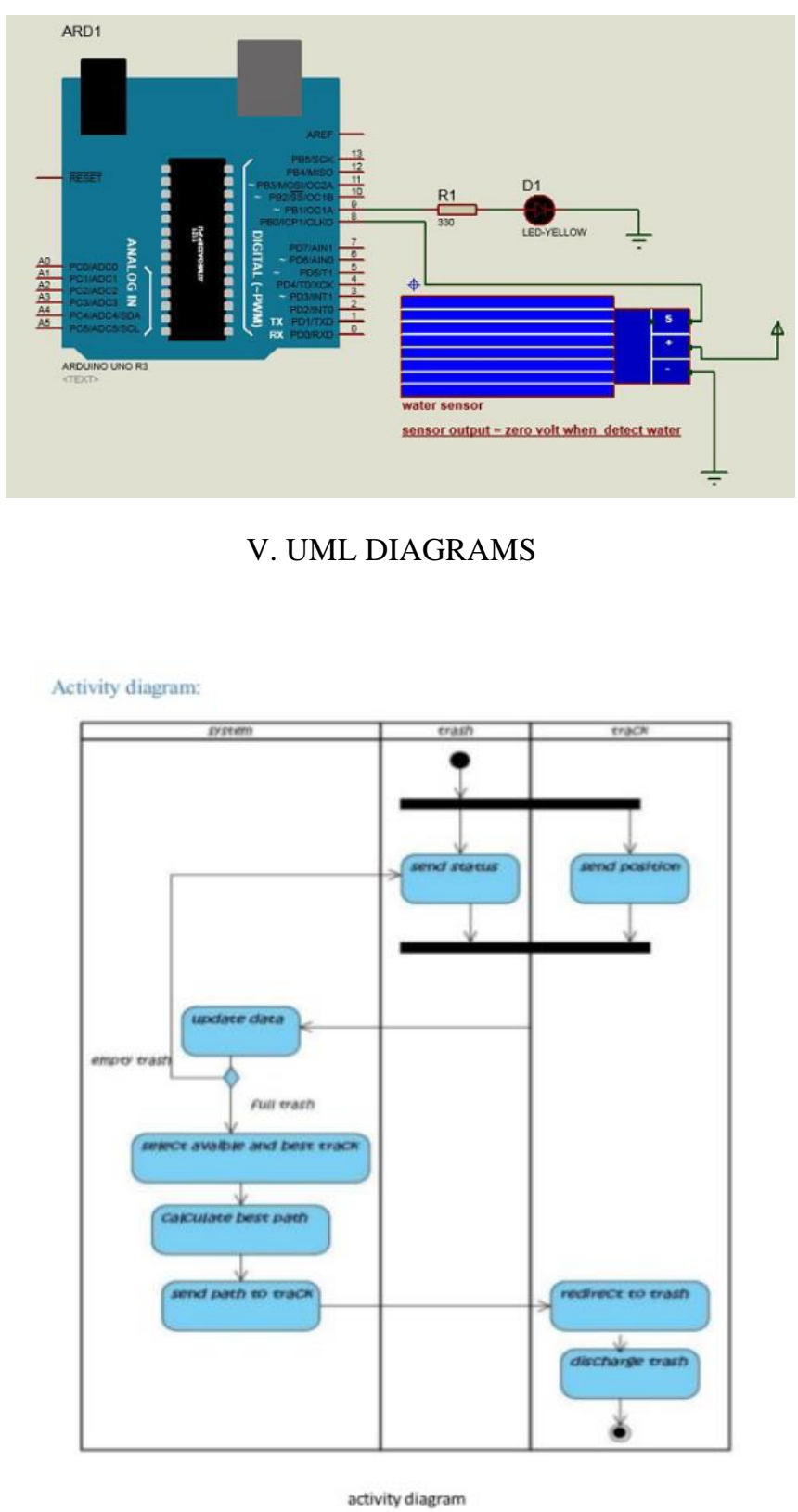

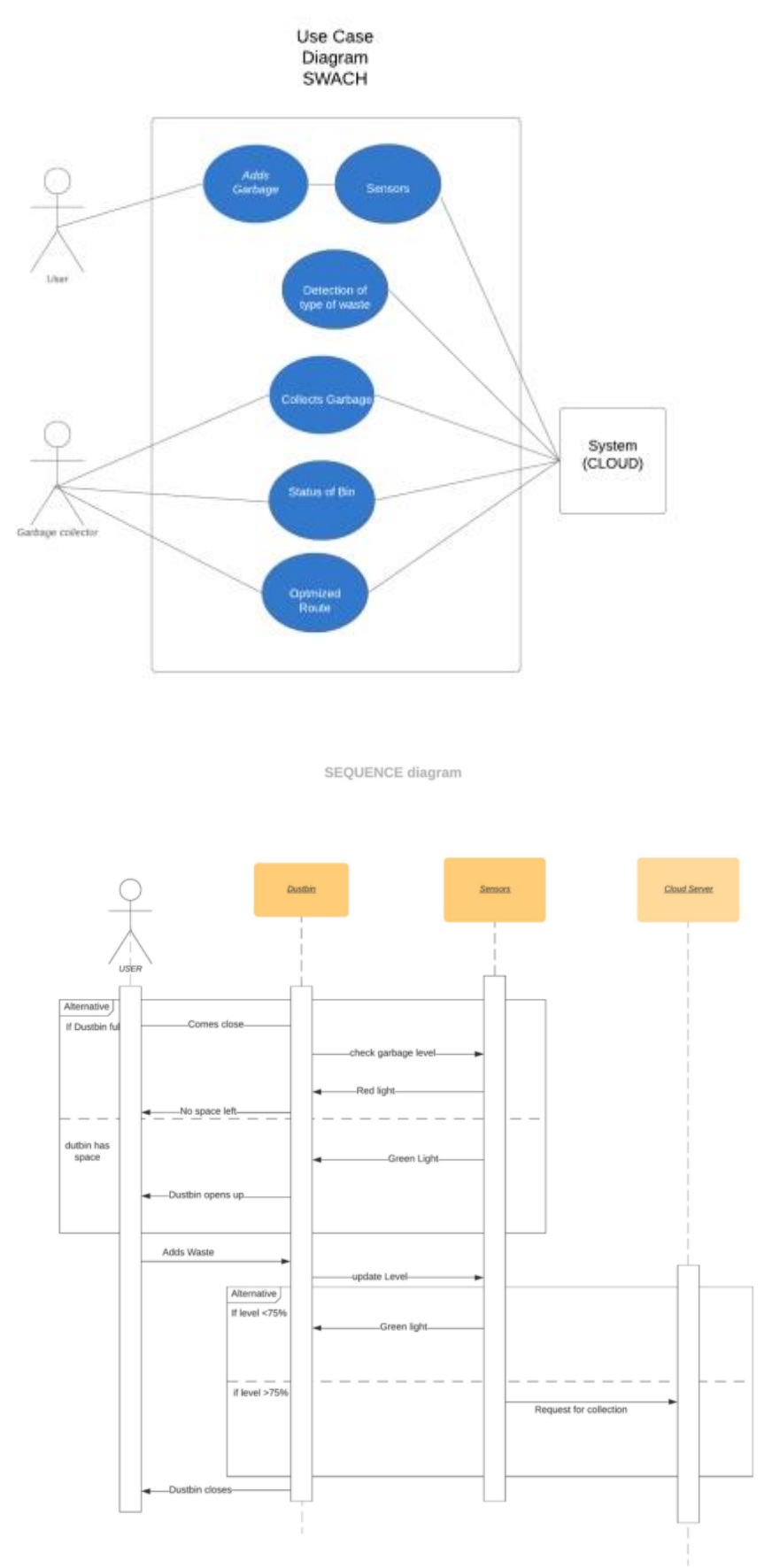

\section{CONCLUSION}

Solid waste collection in recent years is somewhat stagnant way. We have proposed a more efficient waste management system based on the Internet of Things concept that has intelligent management of all garbage bins located throughout the city with proposed features like resource optimization as well as time management. We have developed an application based on android platform, in which real-time information about garbage bin is shown in the graphical form on the map so garbage collector truck driver can go directly to the place where there is a need to empty the bin. The automatic segregation of wet and dry waste proves useful to identify economic value of waste and also manage the waste efficiently. Furthermore the system can be made more greener and cleaner by utilizing renewable and clean sources of energy. Many advancements can be done, which include detecting metallic, glass and plastic waste. Managing solid waste efficiently will be a huge leap towards greener, cleaner and smart cities.

\section{REFERENCES}

[1] U. Housing, and M. OTB, "Smart cities Ranking of European medium- sized cities," http://www.smart-cities.eu.

[2] F. Delicato, P. Pires, T. Batista, E. Cavalcante, B. Costa, and T. Barros, "Towards an IoT ecosystem," In Proceedings of 1st ACM International Workshop on Software Engineering for systems-ofSystems, SESoS'13, Montpellier, France, pp. 25-28, July 2013.

[3] H. Lingling, L. Haifeng, X. Xu, and L. Jian, "An Intelligent Vehicle Monitoring System, Based on Internet of Things," In Proceedings of 7 th IEEE International Conference on Computational Intelligence and Security (CIS), Hainan, pp. 231233, December 2011.

[4] K. Mahajan and J. Chitode, "Zig-Bee Based Waste Bin Monitoring System," International Journal of Engineering Sciences \& Research Technology, 3(2), Feb 2014.

[5] S. Gupta and P. Kumar, "Real Time Solid Waste Monitoring and Management System: A Case Study of Kanpur City," International Journal of Science, Environment and Technology, 4(2), April 2015.

[6] V. Bhor, P. Morajkar, A. Deshpande, "Smart Garbage Management System," International Journal of Engineering Research \& Technology, 4(3), March 2015.

[7] N. Sharma, N. Singha, and T. Dutta, "Smart Bin Implementation for Smart Cities," International Journal of Scientific \& Engineering Research, 6(9), Sept 2015.

[8] https://www.arduino.cc/en/Main/ArduinoBoardUno.

[9] http://sensorwiki.org/doku.php/sensors/ultrasound

[10] https://www.sparkfun.com/products/12751.

[11] https://www.arduino.cc/en/Main/Software 